\title{
Preterm birth - Effects on oral cavity
}

\author{
Shaik Ali Hassan ${ }^{1 *}$, Sumit Bhateja ${ }^{2}$, Geetika Arora ${ }^{3}$ \\ ${ }^{1}$ Dental Surgeon, ${ }^{2} \mathrm{HOD},{ }^{3}$ Reader, ${ }^{1,2}$ Dept. of Oral Medicine, ${ }^{3}$ Dept. of Public Health Dentistry, ${ }^{1,2}$ Manav Rachna Dental \\ College, Faridabad, Haryana, ${ }^{3}$ Inderprastha Dental College \& Hospital, Ghaziabad, Uttar Pradesh, India
}

\section{*Corresponding Author: Shaik Ali Hassan}

Email: alishaikhassan@gmail.com

\begin{abstract}
Preterm and low birth weight youngsters contain around $6 \%$ of every live birth. It is presently a verifiable truth that untimely kids experience numerous oral inconveniences related with their preterm births. Rashly conceived newborn children have a short pre-birth advancement period and they are inclined to numerous genuine restorative issues during the neonatal period, which may influence the improvement of oral tissues. In this review article we will show about how the preterm birth affects the oral cavity.
\end{abstract}

Keywords: Preterm birth, Enamel, Euption, Occlusal relationship.

\section{Introduction}

Preterm birth (PTB) is the critical purpose behind perinatal mortality and depressingness in the many countries, with a normal recurrence of $5 \%-13 \%$. $^{1-3}$ Although propels in neonatal consideration have prompted a decrease in the neonatal death rate, babies conceived rashly stay at a danger of building up a wide cluster of present moment and long haul confusions, for example, respiratory, gastrointestinal and neurodevelopmental disabilities. Several hazard factors have been related with PTB, among these, intrauterine disease has developed as one of the most significant variables. Notwithstanding this, PTB can't be viewed as a one of a kind infection but instead a disorder described. Periodontal ailment has been appeared to convey an expanded hazard for the method of reasoning for this affiliation depends on the recommendation that periodontitis may prompt maternal and fetal aggravation, along these lines setting off the basic pathway of preterm parturition disorder including expanded uterine contractility, cervical maturing and decidua/film activation ${ }^{4-7}$ dental caries, described as a constrained decimation of the tooth and its structure by the acidic symptom made by the microorganisms during the dietary sugar fermentation, ${ }^{8}$ is one of the critical oral medicinal issues in made countries, the effects of dental caries on pregnancy. Various etiological elements for untimely births exist, a significant number of which are related with maternal and fetal maladies, however regularly the causes remains obscure. Prematurechildren with low birth weight or very low birth weight are at more serious hazard for short and long haul entanglements like hyperbilirubinemia, perinatal asphyxia, respiratory, cardiovascular, gastrointestinal, neurological issues and nourishing insufficiencies. It mainly effects oral enamel, tooth eruption and occlusal relationships.

\section{Preterm birth affects enamel}

Tooth enamel is the main hard tissue in the body that isn't redesigned. Subsequently, the entirety of the adjustments in the structure brought about by affronts during its improvement are for all time enrolled.Preterm youngsters showed an assortment of changes in the enamel like less enamel thickness, expanded unpleasantness, pits, and so forth superficially.

In the preterm youngsters, the prenatally framed enamel is the most diminished - at a degree of around 5 to multiple times the thickness of the enamel of fullterm youngsters, which straightforwardly reflects the abbreviated term in the pre-birth phase of enamel arrangement. Similar discoveries have been appeared by Grahnen et $\mathrm{al}^{9}{ }^{9}$ they likewise discovered diminishing in enamel thickness in low-birth-weight babies when contrasted and full-term. The diminished enamel in preterm youngsters is probably going to 
have come about because of both suspension/decrease of ameloblastic movement and the decreased stock of mineral to the creating teeth.

The pace of juxtaposition of human enamel has been assessed to be $0.023 \mathrm{~mm}$ per day. The enamel shows up unpleasant, granular, and ineffectively mineralized on the grounds that rashly conceived newborn children have a generous pace of formative imperfections of enamel. They likewise will in general have low calcium stores and upset calcium digestion, with the least birth-weight youngsters most seriously affected. ${ }^{10}$ This may be on the grounds that of the explanation that in preterm youngsters, the significant piece of the enamel is mineralized after birth and may in this way be exposed to various variables which may upset the mineralization.

The postnatal enamel frequently had halfway a zone of hypomineralized enamel that might be ascribed to unsettling influences in calcium metabolism $^{11}$ they are generally situated on the essential teeth experiencing mineralization around the hour of the untimely birth, for example the essential incisors, canines and first molars, despite the fact that the second essential molars may likewise be included. It was recently believed that enamel problems were constrained to the essential dentition just, as the changeless teeth have not yet started their arrangement at the hour of the preterm birth.

\section{Preterm birth affects eruption of tooth}

Ejection of deciduous teeth and their shedding pursued by emission of perpetual dentition is an organized consecutive and age-explicit occasion, and is considered as a significant achievement during kid's advancement.

Racial, ethnic, sexual and singular variables can impact emission and are generally considered in deciding the models of typical ejection. The essential teeth typically create from midgestation until the finish of the principal year of life. This procedure might be disturbed in preterm newborn children by healthful inadequacies, presentation to specific prescriptions, and awful oral controls.

It has been recommended that healthful inadequacies in early postnatal life assume a job in the advancement of damaged or deferred dentition. The planning of tooth ejection in rashly conceived kids has been seen as postponed, despite the fact that it has additionally been accounted for that development of both the essential and changeless dentition doesn't vary apparently among pre-and full-term children ${ }^{12}$ Factors thought to be identified with deferred tooth emission are short gestational period ${ }^{13,14}$ low birth weight $^{15}$ and neonatal components, including inconveniences of rashness, foundational scatters, length of oral intubation, normal weight.

\section{Preterm birth effects occlusal relationship}

Different ecological components includingaggravations by and large wellbeing and development in youth, masticatory muscle action, dietary factors ${ }^{16}$ mouth breathing, oral propensities, the mother's and kid's nourishment and wellbeing condition, and other perinatal components, may impact the dentition during the occlusal advancement period and the development of the jaws. The development and improvement of dentition proceeds from about the age of 5 weeks in utero until roughly 20 years postnatally. Varieties exist between people in the beginning and bearing of changes, and in the aggregate augments in curve length, broadness and circumference. ${ }^{17}$

The adjustments in maxillary and mandibular curve length are not persistent during the improvement of the dentition, be that as it may, happen as development periods, for the most part from 4 to 6 and 10 to 14 years old. The mandible is made out of various morphogenetic what's more, practical units, among which the condyle is viewed as a development zone that is influenced by useful changes. The impact of the working of the masticatory muscles has been exhibited in creature examines, which have indicated that expanded masticatory capacity may prompt expanded sutural development and bone pairing, and diminished muscle capacity to an abatement in bone mineral mass.

Oral propensities, for example, thumb sucking, mouth relaxing or then again tongue pushing, and furthermore oromuscular powers influencing the creating dentition in developmental periods, are significant as etiological elements for malocclusions. ${ }^{18,19}$ Huge tonsils can decrease the space in the mouth and cause the tongue to be low and 
pushed forward, squeezing against the teeth of the lower jaw. ${ }^{20,21}$

\section{Conclusion}

Preterm birth is a marker of enamel abandons and is a contributing variable of deferred oral development and advancement. Thinking about the problematic conditions and the dangers that these youngsters are exposed to in their development procedure, improvement and adjustment to extra-uterine life. so everything including dental problems has to be taken into consideration.

\section{Source of Funding}

None.

\section{Conflict of Interest}

None.

\section{References}

1. Goldenberg RL, Culhane JF, Iams JD. Epidemiology and causes of preterm birth. Lancet 2008;371:75-84.

2. Slattery MM, Morrison JJ. Preterm delivery. Lancet 2002;360:1489-97.

3. McCormick MC. The contribution of low birth weight to infant mortality and childhood morbidity. $N$ Engl J Med 1985;312:82-90.

4. Saigal S, Doyle LW. An overview of mortality and sequelae of preterm birth from infancy to adulthood. Lancet 2008;371:261-9.

5. Jeffcoat MK, Geurs NC, Reddy MS. Current evidence regarding periodontal disease as a risk factor in preterm birth. Ann Periodontol 2001;6:183-8.

6. Offenbacher S. Maternal periodontal infections, prematurity, and growth restriction. Clin Obstet Gynecol 2004;47:808-21.

7. Jarjoura K, Devine PC, Perez-Delboy A. Markers of periodontal infection and preterm birth. Am J Obstet Gynecol 2005;192:513-9.

8. Hatton ME. A measure of the effects of heredity and environment on eruption of the deciduous teeth. J Dent Res

9. $1950 ; 34: 397-401$.
10. Grahnen H, Larsson PG. Enamel defects in the deciduousdentition of prematurely born children. Odont Revy 1958;9:193-204.

11. Tsang RC, Light IJ, Sutherland JM, Leiman KLI. Possiblep athogenetic factors in neonatalh ypocalcaemoifa prematurity the: role of gestation, hyperphosphataemihay, pornagnesaemiuari, narycalcium loss and parathormoner esponsiveness. J Pediatr 1973;82(3):423-9.

12. Suckling. Developmental defects of enamel: historical and Present-day perspectives of their pathogenesis. $A D R$ 1989;3(2):87-94.

13. Backström MC, Aine L, Mäki R, Kuusela A-L, Sievänen H, Koivisto A-M, Ikonen R-S, Mäki M. Maturation of primary and permanent teeth in preterm infants. Arch Dis Child Fetal Neonatal Ed 2000;83(2):104-8.

14. Golden NL, Takieddine F, Hirsch VJ. Teething age in prematurely born infants. AJDC 1981;135:903-4.

15. Seow WK, Humphrys C, Mahanonda R, Tudehope DI. Dental eruption in low birth-weight prematurely born children: a controlled study. Pediatr Dent 1988;10(1):3942.

16. Trupkin DP. Eruption patterns of the first primary tooth in infants who were underweight at birth. ASDC J Dent Child 1974;41:279-82.

17. Varrela J. Occurrence of malocclusion in attritive environment: a study of a skull sample from southwest Finland. Scand Dent Res 1990;98:242-7.

18. Moorrees CFA. The dentition of the growing child. Harvard University Press, Cambridge, Massachusetts 1959;88-101.

19. Nanda RS, Khan I, Anand R. Effect of oral habits on the occlusion in preschool children. J Dent Child 1972;39:449452.

20. Larsson E. Artificial sucking habits: etiology, prevalence and effect on occlusion. Int J Orofacial Myology 1994;20:10-21.

21. Ricketts RM. Respiratory obstruction syndrome. Am J Orthod 1968;54:495-507.

22. Myllärniemi S. Malocclusion and childhood health. Proc Finn Dent Soc 1972;68:286-91.

How to cite this article: Hassan SA, Bhateja S, Arora G. Preterm birth - Effects on oral cavity. J Paediatr Nurs Sci 2019;2(4):99-101. 